\title{
Bactrins e quebra-pedras
}

Melvina Afra Mendes de Araújo ${ }^{1}$

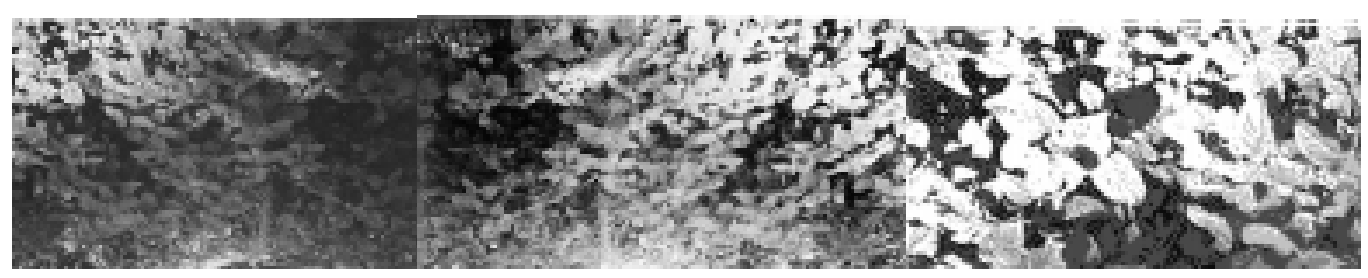

ARAújO, M. A. M Antibiotics and healing plants, Interface _ Comunicação, Saúde, Educação, v.4 , n.7, p.103-10, 2000 .

This article discusses issues concerning biomedical logic vis à vis popular medical lore. Its starting point is the Plant Therapy Implementation Project at the Municipal Healthcare Network of the town of Londrina (state of Paraná, Brazil), as well as the cosmological elements that guide the practice of curing with medicinal herbs.

KEY WORDS: Anthropology; medicinal plants; popular medicine; state medical coverage; alternative therapies.

Neste artigo busco discutir questões referentes ao encontro entre as lógicas biomédica e popular, partindo da análise do Projeto de Implantação da Fitoterapia na Rede Municipal de Saúde de Londrina/Pr e de elementos da cosmologia que orienta as práticas de cura com ervas medicinais.

PALAVRAS-CHAVE: Antropologia; plantas medicinais; medicina popular; cobertura de serviços públicos de Saúde; terapias alternativas.

\footnotetext{
${ }^{1}$ Doutoranda em Antropologia Social, Faculdade de Filosofia, Letras e Ciências Humanas, Universidade de São Paulo; bolsista da Fundação de Amparo à Pesquisa do Estado de São Paulo (Fapesp). <melvina@usp.br>
} 
Elaborado a partir de pesquisa realizada com um grupo biomédico e outro popular ${ }^{2}$, em Londrina/Pr, no período compreendido entre os anos de 1995 a 1998, este artigo trata dos dilemas inerentes à tentativa de diálogo entre dois universos culturais distintos. O ponto de partida da pesquisa é a discussão sobre a implantação da fitoterapia na Rede Municipal de Saúde de Londrina, colocando em pauta o relacionamento entre as lógicas biomédica e popular através do preceito de "recuperação do conhecimento terapêutico popular".

A fitoterapia foi objeto de uma longa discussão que resultou na elaboração do Projeto de Implantação da Fitoterapia na Rede Municipal de Saúde de Londrina. Esse projeto, apesar de ter contado com o apoio dos dirigentes da Autarquia do Serviço Municipal de Saúde de Londrina (gestão 93-96) e de ter sido objeto de reivindicação de setores do movimento popular em saúde, não chegou a ser concretizado. Assim, arrisco afirmar que a intenção de se implantar a Fitoterapia encerrou um encontro entre duas lógicas tentado politicamente e um desencontro de dois mundos no plano da cognição.

Pretendo, pois, analisar o Projeto de Implantação da Fitoterapia na Rede Municipal de Saúde de Londrina (Prefeitura de Londrina, 1996) e alguns elementos da cosmologia que orienta as práticas de cura da população residente na área de abrangência da Unidade Básica de Saúde do Conjunto Habitacional São Lourenço, lançando luz sobre os problemas referentes ao encontro entre as lógicas biomédica e popular.

\section{Bactrins e quebra-pedras}

A elaboração do projeto de implantação da Fitoterapia na Rede Municipal de Saúde de Londrina teve como pano de fundo as discussões acerca da humanização e universalização da atenção à saúde nos serviços oficiais. No momento em que o projeto estava sendo elaborado (entre os anos de 1993 e 1996), a cidade era administrada por um grupo político que tinha à frente o Partido dos Trabalhadores e o setor saúde contava com aguerridos defensores dos princípios norteadores do Sistema único de Saúde - SUS. Dentre os princípios do SUS o que mais interessa ressaltar neste momento - por ter sido fundamental na orientação da gestão municipal e, de maneira particular, da área de saúde - diz respeito à participação popular.

Partindo do pressuposto de dar voz à população e tentar implementar formas mais humanizadas de atenção à saúde, que respeitassem as concepções $e$ práticas de cura próprias da população a que se destinam os serviços públicos de saúde, o grupo de Fitoterapia da Rede Municipal de Saúde de Londrina passou a organizar esforços para elaborar um projeto que levasse em conta algumas questões consideradas importantes para uma aproximação com a população, lançando algumas críticas ao próprio savoir faire biomédico.

A discussão sobre a implantação da fitoterapia emerge de um processo de autocrítica da biomedicina, em que alguns de seus pressupostos são colocados sob suspeita. A crítica lançada pelo grupo de Fitoterapia da Rede Municipal de Saúde de Londrina à biomedicina refere-se à desconsideração da influência dos fatores emocionais nos processos de adoecimento e cura, bem como à
${ }^{2}$ A pesquisa de campo foi realizada com o grupo de Fitoterapia da Rede Municipal de Saúde de Londrina e com a população residente na área de abrangência da Unidade Básica de Saúde do Conjunto Habitacional São Lourenço, região sul da cidade. Em ambos os grupos a pesquisa teve como base a observação participante, sendo que, no primeiro, o trabalho foi desenvolvido a partir de reuniões semanais (nos anos de 1995 e 1996) organizadas, particularmente, para discussãoe elaboração do Projeto de Implantação da Fitoterapia na Rede Municipal de Saúde de Londrina. Com o grupo popular, a pesquisa foi desenvolvida a partir da convivência com a população e mediante entrevistas abertas e não estruturadas realizadas ao longo de quatro anos, com as pessoas indicadas como

conhecedoras de "remédios caseiros" ou de "remédios de plantas". Foram nove mulheres entrevistadas (não por escolha da pesquisadora, mas por terem sido indicadas pela população). 
${ }^{3}$ A proposta de "resgatar os conhecimentos terapêuticos populares" faz parte do $4^{\circ}$ Plano Operativo do Projeto UNI Londrina.

${ }^{4}$ Um apanhado sobre os princípios ordenadores da medicina de origem científica pode ser encontrado em Araújo (1998).

${ }^{5}$ Os princípios do catolicismo popular encontrados entre a população pesquisada já foram descritos por autores como Brandão (1986), Zaluar (1973e

1980), Camargo \&

Souza (1973).

Como observam estes autores, 0 princípio da reciprocidade, um dos preceitos mais importantes do universo ético do catolicismo popular, orienta as normas de conduta que os homens devem manter entre si e com as divindades. A manutenção ou quebra dessas relações são consideradas, pelo grupo pesquisado, responsáveis pela boa sorte e pelos infortúnios, dentre os quais estão incluídas as

doenças

classificadas como espirituais. fragmentação do corpo e seus males em virtude da supervalorização das especialidades. Os diagnósticos centrados principalmente no uso de tecnologias afastam, de acordo com as concepções do grupo de Fitoterapia, o médico do paciente, dificultando a existência de uma cumplicidade entre eles, fator fundamental para um melhor êxito do tratamento.

Incluindo-se entre as chamadas medicinas alternativas - formas de tratamento do corpo e suas doenças que propõem uma reação aos princípios da medicina de origem científica - a Fitoterapia é vista, pelo grupo aqui analisado, como portadora de uma possibilidade de mediação entre os conhecimentos curativos biomédico e popular. A reação à biomedicina, neste caso, pressupunha a incorporação de um conhecimento popular à prática biomédica. Porém, se, num primeiro momento, a fitoterapia se organizou em contraposição à pratica médica convencional (pelo menos nos moldes em que foi proposta pelo grupo da Rede Municipal de Saúde de Londrina), acaba por manter-se fiel aos princípios orientadores da medicina científica.

$\mathrm{O}$ argumento de que a implantação da fitoterapia funcionaria como um impulso para a aproximação entre o par médico-paciente, está baseado no fato de que o uso de plantas nos processos de cura é comum nos meios populares. Esta seria, segundo o grupo de fitoterapia, uma forma de "resgatar o conhecimento terapêutico popular" ${ }^{3}$, respeitando suas formas de compreender a doença e o corpo. No entanto, se, por um lado, o grupo de fitoterapia propunha a incorporação das ervas nos procedimentos terapêuticos das Unidades Básicas de Saúde, por outro, estas ervas não poderiam ser utilizadas nem indicadas em seu estado natural. Mais que isso, uma planta apenas poderia ser recomendada após a comprovação científica de seu princípio ativo.

Dessa forma, o grupo de fitoterapia, apesar de pretender incorporar uma prática terapêutica distinta daquelas já oficialmente adotadas no âmbito da medicina de origem científica e de tecer críticas ao savoir faire biomédico, acaba, em sua intenção de incorporar à prática biomédica elementos das práticas terapêuticas populares, pinçando elementos das práticas de cura populares $e$ os classificando a partir dos princípios ordenadores da medicina de origem científica ${ }^{4}$.

Entretanto, a incorporação das ervas medicinais de acordo com os critérios científicos estabelece uma distinção entre o seu uso nos meios populares $e$ aquele que tem lugar no interior das práticas biomédicas, pois, entre a população estudada, a utilização das ervas apenas faz sentido se relacionada a uma maneira particular de se perceber o mundo, em que doença e cura são vistas como inerentes à vida.

Tendo como pano de fundo os princípios do catolicismo popular $^{5}$, em que a reciprocidade $e^{6}$ é fundamental, o corpo é percebido como espaço privilegiado da manifestação de desajustes nas relações dos homens entre si e deles com as divindades. Dessa forma, os desequilíbrios nessas relações integram o leque de possibilidades de causação dos males, sendo a cura concebida como um processo em que se busca o reequilíbrio do corpo e da alma.

A compreensão da visão de mundo da população pesquisada é fundamental para que se possa entender o sentido da utilização das ervas medicinais, dietas alimentares e restrições impostas às

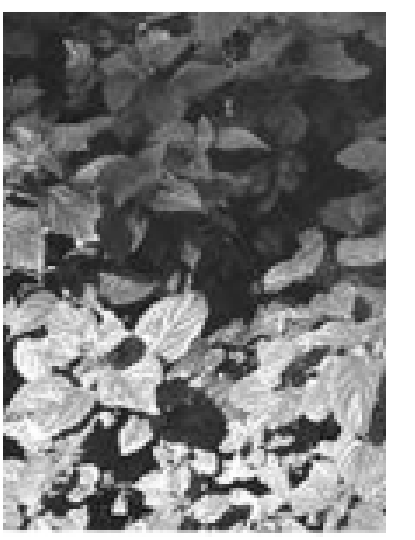

agosto, 2000 


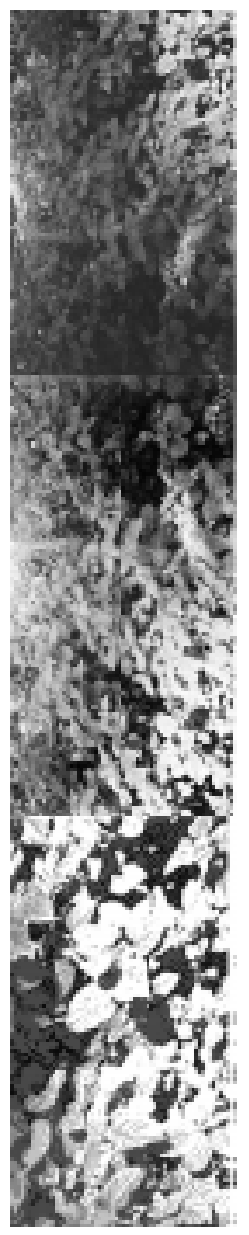

pessoas que atravessam momentos da vida em que cuidados especiais parecem necessários. Algumas categorias de pessoas são consideradas em situação de risco, precisando então de cuidados especiais. São incluídas neste grupo a grávida - a quem não se recomenda a ingestão de remédios e o lombriguento (aquele que tem lombrigas ou bichas em demasia), por exemplo.

Segundo a população pesquisada, à grávida e ao lombriguento (particularmente se se tratar de uma criança) não deve ser negada a satisfação do desejo de comer ou beber. Aqui entra em pauta um princípio fundamental para a organização dessa lógica, que é o princípio da reciprocidade. Explico melhor. De acordo com as concepções deste grupo, existe em cada um de nós uma bicha chefe que comanda as vontades do corpo e que é responsável pela manutenção da vida. Entretanto, para que a bicha chefe dê o ânimo necessário à continuação da vida é preciso alimentála, ou seja, é preciso que suas vontades sejam satisfeitas. Porém, a satisfação dos desejos da bicha chefe não isenta seu portador do risco da morte, pois à medida que recebe alimentos ela vai se reproduzindo $e$ quanto mais se reproduz, mais alimentos exige. Há um limite a partir do qual o hospedeiro não mais dá conta de satisfazer os desejos de seus hóspedes. Nesse caso, ou ele toma algumas precauções no sentido de eliminar o excesso de bichas (indica-se para esse fim a ingestão de purgantes) ou corre o risco de sofrer um ataque de bichas. O ataque de bichas ocorre, segundo essa concepção, quando, não mais encontrando alimentos suficientes na barriga do seu hospedeiro, as bichas migram para outras partes do corpo - particularmente os orifícios superiores ${ }^{7}$ - podendo até causar sua morte.

Ao contrário do lombriguento, em que quem cria é a bicha chefe que ele carrega na barriga, a grávida é criadora da vida do ser que leva em seu ventre. No entanto, a satisfação dos desejos desse ser é fundadora de uma aliança geracional cuja direção da doação deverá ser invertida posteriormente. Se durante a gravidez e a infância é a mãe a responsável pela satisfação dos desejos do filho, quando ela for velha é deste a responsabilidade de lhe dar sustento. Nesse sentido, é interessante observar que as explicações nativas acerca da existência de manchas ou marcas na pele recaem sobre a não satisfação de um desejo de comer ou beber durante o período de gestação de seu portador. A presença de manchas ou marcas congênitas na pele seria denunciadora de uma situação de falta. Considerando que quanto mais for considerada boa mãe, melhores são as chances de uma mulher ser amparada pelos filhos na velhice, esta é uma questão tratada com grande zelo entre o grupo pesquisado.

As considerações acerca do lombriguento e da grávida apontam no sentido de mostrar que o desejo é bem visto, pelo grupo pesquisado, enquanto criador de vida, mas temido quando ameaça suprimir a razão pela imposição da satisfação dos desejos e a continência alimentar, das ações e paixões, pelo pecado. Essas concepções estão ancoradas num universo lógico em que a vida na terra é pensada como lugar da dor, do sofrimento e da incompletude, sendo a plenitude apenas possível de ser alcançada após a morte, caso a alma seja aceita no paraíso $^{8}$.

\footnotetext{
${ }^{8}$ A cosmologia desse grupo é riquíssima e não há aqui espaço para fazer uma análise mais detalhada sobre ela. Desenvolvo essa questão em minha dissertação de mestrado Das ervas medicinais à fitoterapia: encontrose desencontros entre as lógicas biomédicae popular.
} 
O sentido do

termo

reinterpretação

aqui adotado

aproxima-se da

idéia defendida

por Sahlins (1990)

de que a estrutura

é atualizada pela

conjuntura, ou

seja, as

significações são

atualizadas através

da ação. Esse

movimento de

atualização das

significações,

longe de suprimir

uma maneira de

ser de uma

cultura, é o que

faz a estrutura se

manter. Faz-se

necessário, no

entanto, salientar

que Sahlins

(1990), ao

contrário de Lévi-

Strauss (1985;

1993), não pensa

a estrutura como

inconsciente, ma

como um modo

como as

significações se

relacionam com a

cosmologia.
Autores como Marta Campos (1982), Andréa Loyola (1984 e 1987) e Marcos Queiroz (1980 e 1993) fundamentam suas análises sobre as relações entre a biomedicina e as práticas populares de cura no argumento de que estas estão sendo paulatinamente suprimidas por aquelas. Já a abordagem de Elda Rizzo de Oliveira (1985a, 1985b), parte do pressuposto de que as práticas populares de cura fazem parte de um movimento de resistência à cultura dominante, que se expande e tenta destruir todas as outras manifestações culturais. Noutra direção aponta o trabalho de Paula Montero (1985) quando mostra que a medicina popular age nos interstícios da medicina oficial, não se constituindo porém de forma fechada em relação ao sistema biomédico.

As duas primeiras interpretações são, sob meu ponto de vista, insuficientes, pois nem as práticas populares de cura estão desaparecendo, nem existe, no meio popular, um movimento no sentido de oferecer resistência às práticas biomédicas. Essas análises deixam de atentar para o movimento de recriação cultural, em que essas práticas, ao mesmo tempo que estão continuamente se modificando, se perpetuam. Ao buscarem formas descritas por estudos realizados no passado - muitas vezes no meio rural - essas pesquisas deixam de perceber as novas nuances pelas quais os conhecimentos curativos se mantêm e se renovam.

Nesse sentido, faz-se necessário notar as maneiras pelas quais o conhecimento popular de cura encontra para se perpetuar, utilizando-se das brechas deixadas pelo sistema médico oficial. Frente a posturas de negação da validade do conhecimento popular de cura, essa população, ao longo dos anos, criou algumas formas de lidar com os médicos, mantendo e falando de suas práticas tradicionais, sem correr o risco de sofrer reprimendas. Isso poderia ser observado a partir de várias atitudes, mas uma das coisas que mais chamou a atenção foi a denominação de plantas com nomes comerciais de medicamentos industrializados. Entre as ervas medicinais plantadas nos quintais dos meus informantes encontrei anador, dipirona, novalgina, insulina e bactrim.

A denominação de plantas com nomes comerciais de medicamentos industrializados provoca um mal-entendido que funciona no sentido de fazer com que, no diálogo entre médico e paciente, cada um acredite estar falando a mesma linguagem, embora estejam dizendo coisas diferentes. Durante uma consulta, geralmente o médico indaga se o paciente está tomando algum medicamento e qual é. Quando o paciente responde que tomou bactrim, sua resposta tem um impacto completamente diferente daquele causado pela declaração de que se tomou um chá de folhas de uma determinada planta. $\mathrm{O}$ que o médico não sabe é que bactrim é também um nome atribuído a uma erva medicinal.

A incorporação desses nomes deve ser entendida como uma forma de reinterpretar ${ }^{9}$ elementos da biomedicina incluindo-os na lógica que orienta e dá sentido aos cuidados corporais no meio popular. As práticas de cura com ervas medicinais encontradas entre a população pesquisada são, pois, modos de pensar e agir, reinterpretações das novas condições de vida, tendo como base um sistema lógico que ordena e dá sentido aos cuidados corporais, às relações interpessoais e à vida como um todo. Ou seja, as mudanças ocorridas no contexto em que vive esta população - migração do meio rural para o urbano, transformações no estilo de vida, tipo de trabalho, habitação e alimentação, por

$$
\text { agosto, } 2000 \quad 107
$$


exemplo - são pensadas a partir de uma lógica que ordena as novas experiências a que essa população é exposta.

Desse modo, a perspectiva adotada pelo grupo de fitoterapia, quando se propõe a "recuperar" o conhecimento terapêutico popular, apenas é possível em virtude do desconhecimento de que, por detrás dos nomes de remédios industrializados permanecem as ervas e uma lógica própria de sua utilização que inclui também os remédios "dos médicos".

Assim, não cabe falar em "recuperação das práticas terapêuticas populares", como o fez o grupo da Rede Municipal de Saúde de Londrina, visto que apenas pode ser recuperado aquilo que foi perdido e este não é o caso das práticas de cura com ervas medicinais entre a população pesquisada. As práticas de cura com ervas medicinais não só são colocadas em ação como seus agentes utilizam o espaço da Unidade Básica de Saúde para propagar esse modo de cura. Entre uma consulta e outra, enquanto aguardam nas filas de espera, os usuários da Unidade trocam receitas. Quando alguém alcança a cura de um mal que o atormentava há muito tempo, pelo uso de remédios caseiros, geralmente dirigese à Unidade e deixa lá a receita do remédio que o curou. Também lá se tem informação sobre quem conhece as ervas medicinais e sabe curar com elas, bem como onde se pode encontrar determinadas plantas.

A idéia de tentar "recuperar as práticas terapêuticas populares" aponta para a existência de uma dificuldade, por parte dos médicos, dos autores que partem da perspectiva utilitarista ou pensam as práticas populares de cura em contraposição à biomedicina, de perceber que a lógica que orienta essas práticas permanece mesmo sem a rejeição de procedimentos biomédicos.

As práticas populares de cura não precisam recusar a medicina de origem científica para continuarem existindo, pois enquanto forma de devolver ao corpo seu equilíbrio, os procedimentos biomédicos são incluídos e pensados a partir do mesmo arcabouço lógico que orienta e dá sentido à vida. Dessa forma, apesar de utilizar elementos e práticas próprios da biomedicina, a população pesquisada continua mantendo um modo próprio de pensar o mundo. A vitalidade desse modo de pensar e perceber o ser no mundo é garantida justamente por sua capacidade de ressignificar as práticas com as quais se depara em novos contextos.

Assim, não existe incoerência na apropriação do espaço da Unidade Básica de Saúde como um ponto centralizador de informações acerca de tratamentos para os males do corpo e também para aqueles considerados originários da intervenção sobrenatural. Enquanto lugar dedicado à cura, nada mais pertinente que concentrar ali esse tipo de informação.

Como, nesse meio, o princípio que orienta as relações dos homens entre si é o da reciprocidade, os quintais da vizinhança estão sempre à disposição de quem procurar. Além disso, após ter sido "agraciado" com um exemplar de uma planta medicinal desconhecida ou que estava em falta na região, a primeira providência é ir até a Unidade e anunciar onde as pessoas podem encontrá-la.

Assim, com ou sem a aprovação dos médicos, as ervas continuam a fazer parte das práticas populares de cura. É bem verdade que os pacientes não costumam declarar aos médicos que fazem uso das ervas medicinais em seus processos de cura, a menos que haja alguma sinalização, por parte do médico, de aceitação desta prática.

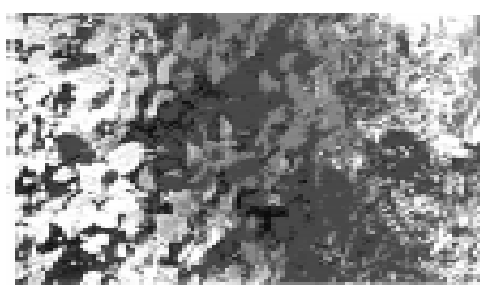


Com as discussões sobre a implantação da fitoterapia passou a haver uma maior displicência em relação à manutenção do sigilo em torno da utilização de chás, garrafadas, emplastos e xaropes preparados em casa, a partir das ervas, entre os pacientes da Unidade Básica de Saúde do São Lourenço. Cabe ressaltar que esta Unidade, durante o período em que foi realizada a pesquisa, possuía uma equipe que tinha um bom relacionamento com a população local e agregava profissionais de saúde simpáticos à Fitoterapia.

Apesar de a abordagem fitoterápica desconsiderar a lógica que orienta o uso das ervas medicinais nos meios populares, sua inclusão no campo de discussão das possibilidades de cura aceitáveis no interior da medicina oficial abre um espaço para que seja produzida uma transformação nas condições de uso do saber tradicional sobre as ervas medicinais. Neste sentido, a discussão do projeto de implantação da fitoterapia foi tomada pela população como uma forma de dar mais credibilidade a suas práticas. Não foram poucas as vezes em que ouvi comentários do tipo "as ervas são tão boas para curar que até os médicos estão querendo aprender a usá-las".

Não obstante os esforços iniciados pelo grupo de fitoterapia e de sua aprovação institucional, essa prática não chegou a ser implantada na rede municipal de saúde de Londrina. No quadro das prioridades estabelecidas para o que a equipe dirigente da Autarquia do Serviço Municipal de Saúde de Londrina considerou como melhoria da qualidade da atenção à saúde, coube à fitoterapia um lugar de menor destaque. Sendo assim, não lhe foi atribuída importância suficiente para que essa prática passasse a fazer parte dos procedimentos terapêuticos desenvolvidos nas Unidades Básicas de Saúde.

Embora haja uma certa concordância em torno da proposição de que a eficácia do tratamento esteja relacionada à compreensão do que diz o paciente, há quase que um consenso, entre os médicos, de que compreender se restringe à "paciência" para ouvir as queixas dos doentes. Dessa forma, apesar de ouvirem continuamente o que dizem os pacientes, os biomédicos permanecem sem se dar conta da cosmologia que sustenta os medos, as considerações referentes às doenças e suas possíveis causas, proibições alimentares $e$ comportamentais frente a determinadas situações. Os procedimentos já consagrados pelo reconhecimento científico continuam a orientar a prática biomédica, impedindo que, além de ouvir, eles possam escutar - no sentido de buscar perceber a lógica que orienta essa forma de pensar - o que dizem seus pacientes.

As discussões lançadas pelo grupo de fitoterapia sinalizaram uma possível abertura da biomedicina em relação a outras práticas de cura. No entanto, apesar da existência de uma crise interna, que aponta para a necessidade de incorporação de outras práticas, houve uma reação contra a abertura, expressa em resolução do Conselho Federal de Medicina (CFM no 1499/98), que proíbe aos médicos a utilização de práticas terapêuticas não reconhecidas cientificamente.

Esta resolução, bem como sua repercussão junto aos médicos partidários de práticas alternativas, ainda precisa ser mais bem estudada, por se tratar de um fato recente. Entretanto, o Conselho Federal de Medicina certamente não teria se dado ao trabalho de lançá-la se essas práticas não estivessem encontrando 
eco entre os médicos, o que demonstra o dilema que está no coração da crise interna pela qual passa a medicina de origem científica, ainda sem solução. Referências bibliográficas

ARAÚJO, M.A. M. Das ervas medicinais à fitoterapia: encontros e desencontros entre as lógicas biomédica e popular. São Paulo, 1998. Dissertação (Mestrado em Antropologia Social). Faculdade de Filosofia, Letras e Ciências Humanas. Universidade de São Paulo.

BRANDÃO, C. R. Os deuses do povo: um estudo sobre religião popular. São Paulo: Brasiliense, 1986.

CAMARGO, C. P. F., SOUZA, B. M. Catolicismo no Brasil. In: Católicos, protestantes e espíritas. Petrópolis: Vozes, 1973.

CAMPOS, M.S. Poder, saúde e gosto: um estudo antropológico acerca dos cuidados possíveis com a alimentação e o corpo. São Paulo: Cortez, 1982.

LONDRINA. PREFEITURA MUNICIPAL. Autarquia do Serviço Municipal de Saúde. Conselho Municipal de Saúde. Rumos da saúde para Londrina: plano municipal de saúde para o biênio 1996-1997. Londrina, 1996.

LOYOLA, M. A. Médicos e curandeiros: conflito social e saúde. São Paulo: Difel, 1984.

LOYOLA, M. A. Medicina popular: rezas e curas de corpo e alma. Ciênc. Hoje, v.6, n.35, p.34-43, 1987.

MAUSS, M. Essai sur le don. In: Sociologie et anthropologie. Paris: Presses Universitaires de France, 1968

MONTERO, P. Da doença à desordem: a magia na umbanda. Rio de Janeiro: Graal, 1985.

MONTERO, P. Magia e pensamento mágico. São Paulo: Ática, 1990.

OLIVEIRA, E. R. O que é benzeção. São Paulo: Brasiliense, 1985a

OLIVEIRA, E. R.O que é medicina popular. São Paulo: Brasiliense, 1985b.

PROJETO UNI. Projeto UNI Londrina: uma nova iniciativa na educação dos profissionais de saúde: união com a comunidade. Londrina, 1992. (mimeogr.)

PROJETO UNI. Prouni/Londrina em ação II: processos e resultados. Londrina, 1994. (Relatório técnico de avaliação do $1^{2}$ ano - outubro de 92 a junho de 94).

PROJETO UNI. Prouni/Londrina em ação III: resultados: ações e realizações do $3^{\circ}$ ano (julho de 94 a junho de 95). Londrina, 1995.

QUEIROZ, M. S. Feitiço, mau-olhado e susto: seus tratamentos e prevenções. Aldeia de Icapara. Relig. Soc., n. 5, p.131-60, 1980.

QUEIROZ, M. S. Estratégias de consumo em saúde entre famílias trabalhadoras. Cad. Saúde Pública, v. 9, n. 3, p. 272-82, 1993.

SAHLINS, M. Ilhas de História. Rio de Janeiro: Zahar, 1990.

STRAUSS, L. Antropologia estrutural. Rio de Janeiro: Tempo Brasileiro, 1985. STRAUSS, L. Antropologia estrutural 2. Rio de Janeiro: Tempo Brasileiro, 1993. ZALUAR, A. Sobre a lógica do catolicismo popular. Dados, n. 11, p.11-39, 1973. ZALUAR, A. Milagre e castigo divino. Relig. Soc., n. 5, p.161-87, 1980.

ARAújO, M. A. M Lógica biomédica y expresión popular, Interface _

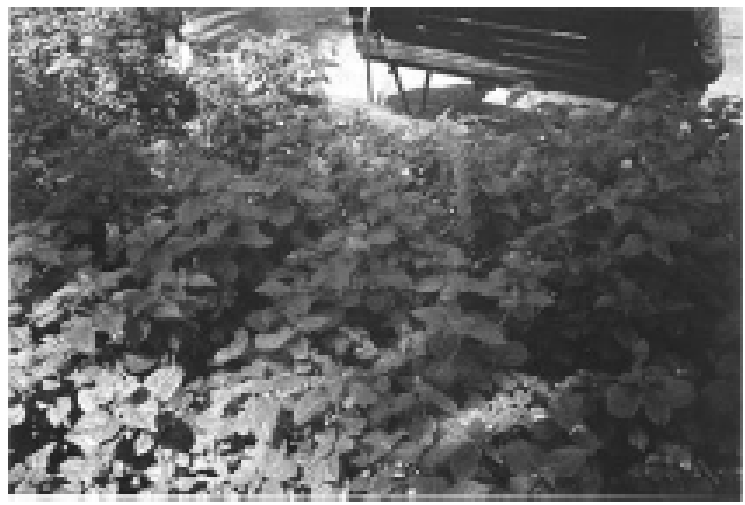
Comunicação, Saúde, Educação, v.4 , n.7, p. 103-10, 2000.

En este artículo busco discutir cuestiones referentes al encuentro entre las lógicas biomédica y popular, partiendo del análisis del proyecto de implantación de la fitoterapia en la red municipal de salud de Londrina, estado de Paraná, Brasil; y de los elementos de la cosmología que orienta las prácticas de cura con yerbas medicinales.

PALABRAS-CLAVE: Antropología; plantas medicinales; medicina popular; cobertura de los servicios públicos de la salud; terapías alternativas. 